\title{
Food Insecurity and Its Determinants in Southern Ethiopia, In Case of Kecha Birra District, Kambata Zone, Ethiopia
}

\author{
Sanait Tadele Negese Tamirat
}

\begin{abstract}
The study examined food insecurity and its determinants in Southern Ethiopia, Kecha Birra district. This study was designed to assess food insecurity and its determinants Kecha Birra district using cross sectional survey data gathered in 2019/20 from a sample of 99 were conducted. To assess food insecurity and its determinants both descriptive and econometrics analysis were used. The data were analyzed by using Statistical Package for Social Science (SPSS). Descriptive statistics such as frequency, mean, percentage, pie chart, bar graph, $t$-test and chisquare were used. Binary logistic regression model was employed to determine factors that influence food insecurity in southern Ethiopia. Results of the study showed that the income of household head, education level of household head, sex of household head, age of household head, access to credit, marital status and household size were found to significantly influence food insecurity. The findings of the study revealed that most of the households were food insecure through the use of HFIAS measurement. These foods in secured households could not cover the required their daily food. The study recommends that any effort in income diversification opportunities in rural area through off farm activities, education, training and extension service and improve livestock productivity could help to enhance household food security in the study area.
\end{abstract}

Keywords: Food, Food insecurity, Logistic regression, Kecha Birra District, Ethiopia

DOI: $10.7176 / \mathrm{FSQM} / 106-04$

Publication date:March $31^{\text {st }} 2021$

\section{Introduction}

Food insecurity is directly related to poverty in world in generally and SSA in particularly. In the world $12 \%$ of the populations were unable to meet their dietary energy requirements and they have suffered from chronic hunger and not having enough food for healthy life. Majority of hungry people 827 million of them live in developing country (FAO, 2013). Particularly food insecurity continues to form a deep seated problem in several SSA countries (FAO, 2010). The situation is not any different in Ethiopia. Ethiopia is one of the poorest countries in the SSA countries with a large portion of its population believed to be living below poverty line and more than 31 million people are undernourished (USAID, 2012; FAO, 2010).

Inadequate food availability has been signed out as one of most important cause of food insecurity and its attribute to among other factor insufficient domestic product and import these has been due to law agriculture productivity and high poverty line which limit access of food because house hold has not sufficient means to pay for the required food. Food insecurity emerged as a key problem and development Challenge in Ethiopia in the early 1970 and become pervasive in subsequent decades. A host of factor include natural \& man made, have resulted in the growing food insecurity problem in many part of country and wide spread poverty in the countries. Other factors contributing to food insecurity are the low level of technology employed in agriculture and the resulting low level productivity of the sector.

According to the study conducted by (Tilaye, 2004), SNNPR were one of the poorest regional economies in Ethiopia, many house hold are only able to produce food to meet their requirement for less than six months of the year. In SNNPR larger parts populations are chronically food insecure and out of these food insecure districts, Kecha Birra district is the one, which is found in the SNNPR in Kambata Zone. The greatest food insecure challenge over all remain in SNNPR, which has seen particularly slow progress in improving access to food with sluggish income growth, high poverty rate, and poor infrastructure which hamper physical and distributional access. The major aggravating factors of food insecurity in study area are shortage of rain fall and erratic nature of rain fall distribution which leads to heavy soil erosion during rainy season. These are the major problem which leads to the existence of food insecurity in the study area.

All most of SSA countries face food deficient. The factor that affecting the living standards and growth prospects include frequent drought, growing expenditure on food production and imports, falling export earnings and rapid population growth. The effect has been pervasive, not only on income of agricultural producers, who include most of Africa poor, but also on supplies of food and raw material for industry, on employment, savings, government revenue and on the demand for good and service produced outside agriculture (Khush, 2012). Ethiopia is among the poorest and most food insecure countries of the Sub Saharan Africa, portion of country's population live below the poverty line and many people died by drought than other problems particularly in the period of the registered and documented recurrent drought epidemics. The countries have been facing challenging problems ranging from those induced by environmental crisis to those caused by demographic and socio economic constraint that adversely affect people is production system. 
In Ethiopia the problem of food insecurity is almost the same with other developing country. World food program stated the common factor that cause household food insecurity in urban area of the country are household size, age of the household, sex of the household, marital status of the household, educational level of the household, dependency ratio, access to credit service, ownership of saving account, total income per adult equivalent, expenditure level(food and non- food item), access to subsidized food source of food availability of food commodity and supply of food commodities (Girma, 2012). According to (Girma, 2012) climate change has the potential to adversely affect net farm revenue of small holder with increasing land fragmentation due to population growth translating to worsening food insecurity situation. Since food security bring in additional socio economics, geographical and political factor, focusing on measure of vulnerability and the development of adaptive capacity to reduce the adverse impact of climate change in rural area of Ethiopia.

In Ethiopia agriculture and livestock production are mostly traditional and heavily depend on the erratic and unpredictable rain fall. As result yields are low and post-harvest losses are high, creating widespread food insecurity. Low productivity due to pests and diseases, drought, declining soil fertility and poor farming method hinder household to create food reserves. Drought shocks have weakened the productive capacity of pastoral and small holder farmers, leading to high dependency on humanitarian support. Consequently, many populations are unable to recover and rebuild herbs and food shock between consecutive drought events. Small land holding in different part of country frequently drought due to climate change and environment degradation has contributed to increased food insecurity for households, especially, in moisture deficit and pastoral areas. Food production is increased extensively through expansion of the area under cultivation, while livestock provides not only food for the producers but of other products which could be sold to provide food or income. Fertilizer used by most studies as a proxy to technology. According to (Adane, 2008), subsistence rearming by its nature is production for direct consumption any farm inputs that augments agricultural productivity expected to boost the overall production this contributes for words attending household food security (Shiferaw, 2023). In the present study, fertilizer usage was expected to increase house hold food production and hence food security.

According to (Girma, 2012), the result of the logit regression model indicted that sex out of ten variables namely house hold size, age of house hold head, house hold head education, asset possession, access to credit service and access to employment were found to be statically significant as determinate of house hold food insecurity in study area. House hold size and asset possession were significant at less than one percent probability level while access to credit service, age of house hold head access to employment were significant at less than $5 \%$ probability level. In addition, the house hold head education was significant at $10 \%$ probability level. House hold size and age at house hold head were found to be positively related with probability of being food insecure whereas access to credit service, asset possession, and house hold head education and access to employment were negatively related with probability of being food insecure. As house hold determinant, regardless of amount, fertilizer utilization generally was found to be very significant and a positive related with food security status. Thus, in term increase own consumption there by results in improved house hold food security status. Food insecurity is no longer seen simply as a fewer of agriculture to produce sufficient food at the national level, but instead as failure of live hoods to guarantee access to sufficient food at the household level (Mesert, 2013).

However, a few studies have been conducted focusing on the different dimensions of rural food insecurity in smallholder rural farming household in Ethiopia, particularly, in SNNPR, and were little focus given to the determinants of household food insecurity of smallholder rural farming household of SNNPR. Systematic and adequate information on the determinants of household food insecurity were not well identified. Further, in the study area there were limited empirical study conducted on the assessments of food insecurity and its determinants of smallholder rural farming households. Therefore, this study was conducted to assess food insecurity and its determinants of small farm households. The general objective of the study is identifying food insecurity and its determinants in Southern Ethiopia, in case of Kecha Birra district.

\section{Materials and Methods}

The study was conducted in Kecha Birra district, Kambata Zone, SNNPR, in the South West central part of Ethiopia about a distance of $282 \mathrm{~km}$ south of Addis Ababa. The total population of the Woreda is 113, 687, of which 55,827 is male and 57,860 is female. The data for study was collected from both primary and secondary sources. Cross-sectional data was collected from the survey of randomly selected smallholder rural farm households. For the primary data collection, specifically designed and pre- tested questionnaire based on the objective of the study, and trained data enumerators was used. The questionnaires schedule was tested at 18 randomly selected farm households in the study area. Both quantitative and qualitative information were collected. The data collection included household's demographic, socioeconomic and environmental characteristics at household level. Secondary information like population number, agricultural inputs and outputs, farm use pattern, rainfall amounts (annual mean and cropping season), temperature and agroecology, etc were also collected. The survey was carried out in the months of May and June 2019.

The study applied probability sampling methods of both simple random sampling and proportional sampling 
methods. To give equal chance the study selected five kebeles by using simple random sampling technique, namely Awaye, Gamasha, Ashira, Buge, and Laada. Then, by using proportional formula, the study selected the respondents from five kebeles households. The way of collecting the data from each kebele was by using random technique, because the houses are not built within municipal plan. The sample size was determined based on the simplified formula given by (Yamane, 1967). Where $\mathrm{n}=$ the sample size, $\mathrm{N}=$ the population size, and $\mathrm{e}=$ the level of precision. $\mathrm{N}=$ the total number of households in the selected Kebeles and $\mathrm{e}=$ acceptable error margin $10 \%$. Based in this, the required sample size was determined as follows.

$$
\mathrm{n}=\frac{\mathrm{N}}{1+\mathrm{N}\left(\mathrm{e}^{2}\right)}=\frac{9229}{1+0.1^{*} 0.1^{*}(9229)}=99
$$

Table 1: Distribution of sample size by kebele

\begin{tabular}{lcc}
\hline Kebele & Number of households $\left(\mathrm{N}_{\mathrm{i}}\right)$ & Total Sample $\left(\mathrm{n}_{\mathrm{i}}\right)$ \\
\hline Awaye $\left(\right.$ Kebele $\left._{1}\right)$ & 1800 & 19 \\
Gamasha $\left(\mathrm{Kebele}_{2}\right)$ & 1845 & 20 \\
Ashira $\left(\right.$ Kebele $\left._{3}\right)$ & 1600 & 17 \\
Buge $\left(\right.$ Kebele $\left._{4}\right)$ & 2012 & 22 \\
Laada $\left(\right.$ Kebele $\left._{5}\right)$ & 1972 & 21 \\
Total & 9229 & 99 \\
\hline
\end{tabular}

$\mathrm{n}_{\mathrm{i}}=$ total number of households selected from kebele $\mathrm{I}(\mathrm{I}=1,2,3,4,5) ; \mathrm{N}_{\mathrm{i}}=$ total number of households in kebele i.

The study used both descriptive method and econometrics model to analyze the collected data. Therefore, descriptive statistics were used to provide an overview of the overall data. In addition, inferential statistics (such as chi-square and t-tests) were employed to provide further insights on factors affecting rural smallholder farm households' food insecurity. Specifically, we use chi-square tests for identifying qualitative factors affecting rural smallholder farm households' food insecurity whereas t-test selected quantitative factors. Binary logistic regression was applied to assess the determinants of the food insecurity (Green, 2003).

$P / Y i=1)=\frac{1}{1+e^{-\left(\beta_{0}+\beta i X i\right)}}$

For simplicity, we write (equation 1 ) as $P / Y i=1)=\frac{1}{1+e^{-Z i}}$

Where $\mathrm{P}(\mathrm{Yi}=1)$ is the probability that a house hold being food insecurity

$\mathrm{Zi}$ is the function of a vector of an explanatory variable, equation (2) is the cumulative distribution function. If $\mathrm{P}$ $(\mathrm{Yi}=1)$ is the probability of being food insecure, then 1-p $(\mathrm{Yi}=1)$ represent the probability of being food secured and is expressed as

$1-\mathrm{P}$

$\frac{1}{1+\theta^{Z i}}$

Thus, we can write as

$$
\frac{P(Y i=1)}{1-P(Y i=1)}=e^{Z i}
$$

Equation (4) simply is the odd ratio, the ratio of the probability that a house hold will be food insecure to the probability that it will be food secured. Taking the natural $\log$ of equation we obtain $L i=\ln \frac{P(Y i=1}{1-P(Y)=1}=Z i--------------------(5)$

Where: Li is the natural logarithm of the odd ratio which is not only linear in the explanatory variable but in the parameter also. Thus, introduction the stochastic error term Ui the logit model can be written as

$\mathrm{Li}=$

$\frac{\ln P(Y i=1}{1-P(Y)=1}=Z i=\beta o+\beta X 1+\beta 1 X 2 \ldots \beta n X n$

$\mathrm{Zi}=\beta 0+\beta 1 X 1+\beta 2 X 2+\beta 3 X 3+\beta 4 X 4+\beta 5 X 5+\beta 6 X 6+\beta 7 X 7+u i$

Where $\beta_{0}$ is intercept $, \beta 1, \beta 2, \beta 3 \ldots \ldots \ldots \beta 7$ are the cofficnt of $X 1, X 2, X 3 \ldots X 7$ respectively (slope of the equation in the model, $X_{1}, X_{2}, X_{3} \ldots . X_{7}$ are age of hhh, sex of hhh, family size, income of the hhh, education level of hhh, marital status and access to credit respectively, $\mathrm{Z}=$ food insecurity status of $\mathrm{hhh}, \mathrm{Ui}=\mathrm{error}$ term which is normally distributed with zero mean and constant variance i.e. $\mathrm{Ui} \sim\left(0.8^{2}\right)$. 
Table 2: List of explanatory variables used for the analysis

\begin{tabular}{lcc}
\hline Definition & Type & Expected sign \\
\hline \hline Education level of hh (edu) & Continuous & - \\
Age of hh (age) & Continuous & - \\
Family size (fsize) & Continuous & + \\
Income level of hh (inc) & Continuous & + \\
Sex of hh (sex) & Dummy/binary & - \\
Marital status (mstatus) & Dummy/binary & - \\
Use of credit (cred) & Dummy/binary & - \\
\hline
\end{tabular}

\section{Results and Discussion}

Sex: As shown in table 3, from total respondent of 99 samples, respondent $42(42.42 \%)$ are food secure and the remaining 57(57.58\%) are food insecure. The result show that from the total respondent 33(33.29\%) are women hhh, among these $12(12.12 \%)$ were food secure and the remaining $21(17.17 \%)$ were food insecure female hhh and $66(66.71 \%)$ are male hhh from which $30(30.30 \%)$ are food secureand36 (36.40\%) are food insecure male hhh. Table 3: Sex Structure versus Food Security

\begin{tabular}{|c|c|c|c|}
\hline \multicolumn{2}{|c|}{ Food security status } & \multicolumn{2}{|c|}{ Sex of the household head } \\
\hline & Male & Female & Total \\
\hline Secure & $30(30.30 \%)$ & $12(12.12 \%)$ & $42(42.42 \%)$ \\
\hline Insecure & $36(36.40 \%)$ & $21(21.17 \%)$ & $57(57.58 \%)$ \\
\hline Total & $66(70.71 \%)$ & $33(33.29 \%)$ & $99(100.00 \%)$ \\
\hline
\end{tabular}

Source: own computation based on data (2019)

Educational: As Shawn Table 4 bellow, in the study area 43(43.37\%) of the sample hhh are found to be illiterate, among this $7(7.07 \%)$ and $36(36.30 \%)$ are food secure and insecure hhh respectively, whereas $40(40.45 \%)$ of sample hhh are primary education, among this20 (20.02\%) are food secure and 20(25.25\%) are food insecure hhh, $9(9.10 \%)$ are secondary education, among them $8(8.08 \%)$ and $1(1.02 \%)$ are food secure and insecure respectively and the rest $7(7.07 \%)$ are above secondary education, all are secure no anyone was food insecure. Table 4: Education versus Food Insecurity

\begin{tabular}{|c|c|c|c|c|c|}
\hline \multicolumn{2}{|c|}{ Food security status } & \multicolumn{4}{|c|}{ Education status of the household head } \\
\hline & Illiterate & Primary & secondary & Above secondary & Total \\
\hline Secure & $7(7.07 \%)$ & $20(20.20 \%)$ & $8(8.08 \%)$ & $7(7.07 \%)$ & $42(42.42 \%)$ \\
\hline Insecure & $36(30.30 \%)$ & $20(25.25 \%)$ & $1(2.02 \%)$ & $0(0.00 \%)$ & $57(57.57 \%)$ \\
\hline Total & $43(37.37 \%)$ & $40(45.45 \%)$ & $9(10.10 \%)$ & $7(7.07 \%)$ & $99(100.00 \%)$ \\
\hline
\end{tabular}

Source: own computation based on data (2019)

Income: Income is the other determinant of food security, from all respondent 33(33.33\%) get the range between $0-500,45(45.45 \%)$ are earn 501-1500, 14(14.14\%) are those who get the range between 1501-3000, 5(5.05\%) are those who get the monthly income between 3001-5000 2(2.02\%) are those who get the monthly income above 5000. $0(0.00 \%)$

Table 5: Income Level versus Food Insecurity

\begin{tabular}{|c|c|c|c|c|c|}
\hline \multicolumn{2}{|c|}{ Food security status } & \multicolumn{4}{|c|}{ Monthly income level } \\
\hline & $<<500$ & 2501-1500 & 1501-3000 & $3001-5000$ & Total \\
\hline Secure & $5(5.05 \%)$ & $26(26.26 \%)$ & $6(6.06 \%)$ & $5(5,05 \%)$ & $42(42.42 \%)$ \\
\hline Insecure & $30(30.28 \%)$ & $22(22.19 \%)$ & $5(5.08 \%)$ & $0(0.00 \%)$ & $57(57.00 \%)$ \\
\hline Total & $33(33.33 \%)$ & $45(45.45 \%)$ & $14(14.14 \%)$ & $5(5.05 \%)$ & $99(100.00 \%)$ \\
\hline
\end{tabular}

Source: own computation based on data (2019)

Access to credit: From the total survey 24(24.31\%) households have access to credit and the 76(75.69\%) have not access to credit. This indicates that in the study area most of farm household head have not access to credit. Among the total household who have not access to credit service $22.22 \%$, and $53.46 \%$ are food secure and food insecure respectively. And $20.22 \%$ are food secure and $4.11 \%$ is food insecure household that has access to credit service.

Table 6: Access to Credit and Food Insecurity

\begin{tabular}{lllr}
\hline Do you have access to credit & Food secure & Food in secured & Total \\
\hline \hline Yes & $20(47.62 \%)$ & $4(19.30 \%)$ & $24(24.31 \%)$ \\
No & $22(52.32 \%)$ & $53(80.70 \%)$ & $75(75.69 \%)$ \\
Total & $42(100.00 \%)$ & $57(100.00 \%)$ & $99(100.00 \%)$ \\
\hline
\end{tabular}

Source: own computation based on data (2019) 


\section{Main factors that affecting food insecurity}

Out of seven independent variables which had been assumed to be significantly related with food insecurity status of the household, the estimation revealed from logistic regression that four variables were statically significant.

Family size of hh: its significant variables. Among the important demographic variables, family size is to be highly significant in determining the probability of farm households' food insecurity in the study area. As house hold size increase by one person the odd ratio, keeping all other variable constant, in the favor of being food insecurity is increased by 1.627 at $1 \%$ level of significance. This indicates that positive relationship between household size and food insecurity. The farm household with large family size, having children of non-productive age, could face the probability of food insecure because of high dependency ratio than farm household with small family size.

Education level of hh: is significant variable: - the odds ratio for household who's educated is 0.208 which is less than one. Since the reference category refers a household whose education is illiterate, the odds ratio of a household who's educated is smaller than that of illiterate household. Illiterate household heads are more likely being food insecure as compared to educated household head. The reverse of EXP (B) isEXP $=\frac{1}{0.208}=4.808$. Thus, illiterate household are 4.808 times more likely to be food insecure as compared to household head that's educated.

Access to credit: logit model analysis revealed that household without access to credit is more likely food insecure as compared to household with access credit service at $1 \%$ level of significance. In other word, the odds ratio in favor of being food insecure increase, other thing remains constant; by 0.0403 as household not get access to credit. Income level of hh: is significant variable all other thing remains constant as income level of the household increase the odds ratio in favor of being food insecure decrease by $0.253(25.3 \%)$ at $1 \%$ level of significance. This implies there is negative relationship between income level and food insecurity of household head.

Table 7: Estimation result of binary logit model

\begin{tabular}{|c|c|c|c|c|c|c|}
\hline Variable & Odds Ratio & Std.Err & $\bar{Z}$ & $\mathbf{P}>|\mathbf{Z}|$ & \multicolumn{2}{|c|}{ [95\% Conf. Interval] } \\
\hline$\overline{\operatorname{sex}}$ & 0.713 & 0.494 & -0.49 & 0.625 & .1835 & 2.7697 \\
\hline age & 0.962 & 0.028 & -1.36 & 0.175 & .9087 & 1.0176 \\
\hline edu & 0.208 & 0.103 & -3.16 & $0.002^{* * *}$ & .0786 & .5510 \\
\hline mstatus & 0.863 & 0.339 & -0.38 & 0.707 & .3995 & 1.8631 \\
\hline fsize & 1.627 & 0.307 & 2.58 & $0.010^{* *}$ & 1.1243 & 2.3546 \\
\hline inc & 0.253 & 0.122 & -2.85 & $0.004^{* * *}$ & .0982 & .6513 \\
\hline Cred & 0.040 & 0.041 & -3.13 & $0.002^{* * *}$ & .0054 & .3004 \\
\hline Cons & -5.061 & \multicolumn{5}{|c|}{$0.000 * * *$} \\
\hline$\overline{L R}$ chi2 (1) & 65.94 & \multicolumn{5}{|c|}{ Pseudo R2 } \\
\hline Prob $>$ chi & 0.000 & \multicolumn{5}{|c|}{ Log likelihood } \\
\hline Number o & obs & \multicolumn{5}{|c|}{$* * * \mathrm{P}<1 \%, * * \mathrm{P}<5 \%$ \& $* \mathrm{P}<10 \%$} \\
\hline
\end{tabular}

Source: own computation based on data (2019). Inferential statistics (such as chi-square and t-tests) were employed to provide further insights on factors affecting household's food insecurity.

\section{Conclusion and Policy Implication}

The objective of the study is to assess food insecurity and its determinants in Kecha Birra district in Kambata Zone. Both primary and secondary sources were used to carry out the study. A total of 99 sample household head were selected randomly (two stage of sampling were applied) from these five Keble. The evidence from the logistic regression shows that education, family size, income level of household and access to credit service was significantly determine the probability of being food insecurity at below $5 \%$ level of significance. The variables like education status, access to credit service and income level of household were negative and strong relationship with being food insecurity in the Woreda. The model also shows that there is a positive and strong relationship between the variable family sizes with being food insecurity in the study area.

Therefore, a serious attention has to be given to limit the increasing population in the study area. This can be achieved by creating sufficient awareness to effective planning in the rural house hold. Further, household heads are advised to reduce the size of their house hold and their dependency ratio. So, this implies government and other body at various level needs to address the problem of food insecurity result from the increase in family size. Expansion and strengthening the off-farm activity by providing training and credit service can supplement their income and gradually relieve the diminishing landholding size. The more household educated the higher will be the probability of educating family member and familiar with modern technology. So, strengthening both formal and informal education and vocational and skill training should be promoted to reduce food insecurity. The expansion of education and access to resource is important in reduction of vulnerability and attainments of food insecurity in the study area. 


\section{REFERENCES}

Adane, T. (2008). Correlate of house hold food insecurity in Daro Tuba Woreda west Hararge zone of orima national regional state, Ethiopia; Master's Thesis paper, Addis Ababa University, Addis Ababa, Ethiopia.

FAO. (2013). The state of food insecurity in the world 2013. The multiple dimensions of food security. Rome. $\mathrm{k}$

FAO. (2010). The state of food insecurity in the world 2010. Addressing food insecurity in protracted crises. Rome.

Girma, G. (2012). Determinate of food insecurity among household in Addis Ababa city, Ethiopia. Aksum University, shire campus.

Green, W. (2003). Econometric Analysis 5th edition prentice hall New York, pp. 780-789.

Khush, G. (2012). Bio fortification of crops for reducing mal nutrition plan biography report 6 ligs -202 .

Mesert, M. (2013). Determinant of house hold food insecurity status in Humbo Woreda, Wolalta Zone snnprs Ethiopia. HaramyaUniversity Ethiopia.

Shiferaw, F. (2023). determinant of food security in southern Ethiopia; A selected paper presented of the 2003 American agricultural economics association meeting in Montreal, Canada.

Tilaye, T. (2004). Food insecurity extent, determinate and household coping mechanism in Gera Keya Woreda, Oromia region, MA thesis Addis Ababa University, Ethiopia.

USAID. (2012). Tackling food insecurity and malnutrition in Ethiopia through diversification. www.sweet potat oknow ledge .org. Accessed 3/2/2014.

Yamane, T. (1967). Statistics, an Introductory Analysis, 2nd Ed., New York: Harper and Row. 